\title{
A Formação da Freguesia de Nossa Senhora do Jaguari: estudo de caso do bairro rural Anhumas.
}

The Formation of the Parish of Nossa Senhora do Jaguari: case study of the rural district of Anhumas.

La Formación de la Parroquia de Nuestra Señora del Jaguari: estudio de caso del barrio rural Anhumas.

\section{Carolina Gonçalves Nunes}

Doutoranda em Urbanismo pela Pontifícia Universidade Católica de Campinas. Arquiteta Urbanista. Mestre em Urbanismo pela Pontifícia Universidade Católica de Campinas. arq.carolina@carolinanunes.com.br

\section{Ivone Salgado}

Professora Titular da Pontifícia Universidade Católica de Campinas (FAU e POSURB- ARQ). Arquiteta Urbanista, Doutorado pelo Institut d'Urbanisme de Paris - Université de Paris XII e Pós-doutorado junto ao Instituto

Universitario di Architettura di Venezia. salgadoivone@puc-campinas.edu.br 


\section{RESUMO}

O presente artigo se insere nas investigações do campo da história urbana e da formação do território procurando desvendar as lógicas de formação de bairros rurais procurando analisar as relações destes bairros com o núcleo urbano principal. Utilizando documentação primária, "os maços de população" da então Freguesia de Nossa Senhora da Conceição do Jaguari, atual município de Bragança Paulista, buscou-se compreender quais foram os primeiros bairros rurais que fizeram parte da formação de seu território. A partir dessa compreensão, nos propomos analisar um estudo de caso investigando o papel do bairro Anhumas na formação de uma rede de núcleos que deram origem as diversas freguesias e cidades da região. $O$ bairro de Anhumas se situa na região de conflito de fronteira entre os estados de São Paulo e Minas Gerais, tendo sido um dos principais acessos para o Estado de Minas Gerais no período do conflito. O bairro de Anhumas vivenciou uma história peculiar na região: abrigou capelas e comércio para os viajantes e moradores que por ali viviam ou passavam; foi passagem para o fluxo de população na corrida pelo ouro; desenvolveu uma economia mista até 1830; foi transformado com a entrada da produção do café na região, quando recebeu escravos, imigrante e vivenciou seu apogeu com a implantação da Ferrovia Bragantina; posteriormente, houve um período de declínio com a desativação da Ferrovia Bragantina; hoje se mantem como um patrimônio a céu aberto, desde que sua localização estratégica perdeu importância com a implantação da Rodovia Fernão Dias na região.

PALAVRAS-CHAVE: Bragança Paulista. Bairro Rural. Anhumas.

\section{ABSTRACT}

This article is part of the investigation of the field of urban history and the formation of the territory, seeking to unravel the logic of formation of rural neighborhoods, trying to analyze the relations of these neighborhoods with the main urban nucleus. Using primary documentation, the "packets of population" of the then Parish of Nossa Senhora da Conceição do Jaguari, in the current municipality of Bragança Paulista, sought to understand the earliest rural neighborhoods that formed part of the formation of its territory. From this understanding, we propose to analyze a case study investigating the role of the Anhumas neighborhood in the formation of a network of nuclei that originated the various parishes and cities of the region. The Anhumas neighborhood is located in the border conflict region between the states of São Paulo and Minas Gerais, and was one of the main accesses to the state of Minas Gerais during the conflict period. The district of Anhumas lived a peculiar history in the region: it housed chapels and commerce for the travelers and residents that lived there or they passed; was passage to the flow of population in the gold rush; developed a mixed economy until 1830; was transformed with the entrance of coffee production in the region, when it received slaves, immigrants and experienced its apogee with the implantation of the Railroad Bragantina; later, there was a period of decline with the deactivation of the Bragantina Railway; today it remains an open-air heritage, since its strategic location lost importance with the deployment of the Fernão Dias Highway in the region.

KEY WORDS: Bragança Paulista. Countryside. Anhumas.

\section{RESUMEN}

El presente artículo se inserta en las investigaciones del campo de la historia urbana y de la formación del territorio buscando desentrañar las lógicas de formación de barrios rurales buscando analizar las relaciones de estos barrios con el núcleo urbano principal. En el siglo XVIII, en el siglo XVIII, en el siglo XVIII, en el siglo XVIII, en el siglo XVIII, A partir de esa comprensión, nos proponemos analizar un estudio de caso investigando el papel del barrio Anhumas en la formación de una red de núcleos que dieron origen a las diversas freguesías y ciudades de la región. El barrio de Anhumas se sitúa en la región de conflicto de frontera entre los estados de São Paulo y Minas Gerais, siendo uno de los principales accesos para el Estado de Minas Gerais en el período del conflicto. El barrio de Anhumas vivenció una historia peculiar en la región: abrigó capillas y comercio para los viajeros y habitantes que por allí vivían o pasaban; fue paso al flujo de población en la carrera por el oro; desarrolló una economía mixta hasta 1830; fue transformado con la entrada de la producción del café en la región, cuando recibió esclavos, inmigrantes y vivenció su apogeo con la implantación del Ferrocarril Bragantina; posteriormente, hubo un período de declive con la desactivación de la Ferrovía Bragantina; hoy se mantiene como un patrimonio a cielo abierto, desde que su ubicación estratégica perdió importancia con la implantación de la Rodovia Fernão Dias en la región.

PALABRAS CLAVE: Bragança Paulista. Barrio residencial. Anhumas. 


\section{Introdução}

As cidades portuguesas fundadas na América não são produto meramente aleatório, sem rigor ou método, fato que demonstraria certo desleixo dos colonizadores em províncias muitas vezes miseráveis, como já consagrado pela literatura sobre o tema. Ao contrário, a produção urbana portuguesa no Brasil se enlaça na paisagem da Colônia, estabelecendo uma conexão com a forma de "se fazer cidade" já conhecida em Portugal.

Segundo Romero Jucá Neto, há na grande maioria das vilas fundadas no período colonial a intenção de executar um padrão. No entanto, o território da Colônia é extenso, o que obriga os condutores do processo privilegiar um lugar em detrimento de outro. Assim, muitas vezes as freguesias e vilas da colônia portuguesa se desenvolviam sem a orientação de um engenheiro militar (personagens caros e escassos na colônia) ou se estagnavam por falta de recursos da câmara para as obras públicas, com resultados que fugiam da orientação inicial da Coroa. (JUCÁ NETO, 2013, 448)

A escolha por locais elevados será uma característica importante nos núcleos urbanos brasileiros fundados no período colonial. Essa relação entre o sítio e o local de implantação de novos núcleos de povoamento é de grande importância para o entendimento da ocupação do interior da Capitania de São Paulo. Verifica-se que as primeiras freguesias fundadas são resultado desta "forma de se fazer cidades", própria do ideário português, que já havia sido desenhada pelos colonizadores.

O historiador Murilo Marx esclarece que o patrimônio religioso surgiu no Brasil de maneira tímida e discreta, constituído por uma gleba de terra que permitia a construção da capela para a formação do casario que abrigaria os pequenos sesmeiros, podendo dar origem ao futuro núcleo urbano. A formação de um povoado principiava, portanto, pela doação de terras por um morador ou conjunto de moradores ao patrimônio de um santo de devoção da Igreja Católica. Estas terras cedidas passavam a constituir um bem sagrado e sobre elas poderia ser erguida uma capela, proporcionando a formação e expansão do povoado e determinando legitimidade da terra, conforme as ordenações eclesiásticas. "De uma parte, ocupava-se um determinado terreno e plantava-se o templo desejado; de outra, propiciava-se a aglomeração de moradias e negócios." (MARX, 1991, p. 41).

Com a expansão e o fortalecimento dos bairros, os moradores que eram muito religiosos reivindicavam mais facilidade de acesso à igreja. $O$ grande número de fiéis existentes num bairro rural gerava a necessidade de se construir um templo para a comunidade, pois nem sempre era possível se deslocar com facilidade até a igreja das freguesias ou vilas.

Segundo Murilo Marx, o número de fiéis aumentava a cada novo povoado que surgia na região. Naquele momento, os moradores se reuniam e solicitavam ao bispado local a autorização para erigir uma capela. Murilo Marx adverte, no entanto, que não era suficiente apenas construir o templo, era fundamental sacralizá-lo. "A sacralização iria tornar esse abrigo 
uma ermida também para a Igreja, uma capela reconhecida como tal, uma capela curada, ou seja, visitada regularmente por um padre." (MARX, 1991, p. 19).

Logo, o conhecimento do território é fundamental; reconhecer os rios que banham a área, o relevo, o clima e demais particularidades gera subsídios para compreender a organização do espaço e a fundação de novas povoações, fossem elas capelas, freguesias ou vilas.

Na Capitania de São Paulo, no período colonial, o bairro rural era formado, em geral, por uma população pequena, de mesma natureza, família e interesses, que passava a ser identificado por um nome. Em princípio, as características físicas do local eram referência para denominar os bairros, como morros ou rios. Localização e nomenclatura serviam para um controle administrativo da coroa portuguesa, que no século XVIII estava engajada em desvendar o sertão e dominar o território. Logo, ter o conhecimento e registro desses bairros rurais (e não somente desprender esforços para o núcleo urbano) era uma forma de controle do território.

\section{A Freguesia de Nossa Senhora da Conceição do Jaguari e seus primeiros bairros rurais.}

Em 1763, após escolhido o espaço apropriado - lugar alto, próximo a água, distante de alagamento, provido de boa luminosidade e ventilação - foi construída a primeira capela do bairro, em homenagem a Nossa Senhora da Conceição, fruto da doação do patrimônio para a Igreja, feito por Antônio Pires Pimentel, considerado pela historiografia local o fundador da cidade de Bragança Paulista. Portanto, em 1763 a população do bairro rural de Jaguari passa a ter uma capela e um território em seu entorno, fruto de doação para a Igreja, para a construção de casas e, consequentemente, geração de renda para o pároco. Inicia-se, assim, o núcleo urbano de Jaguari, subordinado a Cidade de São Paulo, no território da Freguesia de São João do Atibaia.

Após a doação do patrimônio religioso, passa a existir uma primeira configuração urbana no núcleo de Jaguari, com espaço delimitado para a capela e o adro ao seu redor, área sem edificações destinada às festas e encontros religiosos dos frequentadores. Ao redor do adro havia o espaço reservado às demais construções. O complexo seguia uma forma triangular, com acesso à rua pelo limite frontal do adro, a futura Rua Direita, como é possível observar na figura 1. 


\section{Revista Nacional de}

Figura 1: Área da Construção da primeira capela no Bairro Rural de Jaguari. Usando como mapa base de 1905, foi proposta uma ocupação inicial para o local onde foi construída a primeira Capela, em preto. Em verde está a área do adro, Em marrom encontra-se a demarcação dos primeiros lotes e finalmente em laranja está o acesso a Capela, a Rua Direita.

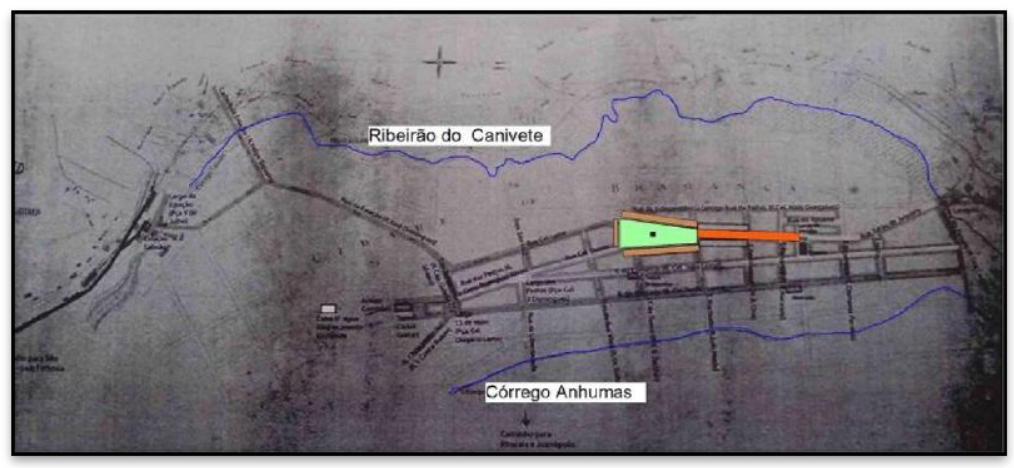

Fonte: Andréa Luri Ishizu, Evolução da malha urbana e arquitetura de Bragança Paulista 1884 a 1967, dissertação de mestrado FAU-USP, 2009, p. 41.

A escolha do local para a formação da Capela de Jaguari foi estratégica, num ponto elevado entre o córrego Anhumas e o ribeirão Canivete.

Para que uma capela se tornasse freguesia era necessário analisar alguns critérios como economia, desenvolvimento e também fatores políticos vinculados à estratégia da Coroa para a conquista e domínio do território. A área em que vivia a população frequentadora de uma determinada capela não era delimitada fisicamente e era subordinada a uma vila, que dava suporte civil a essa população. Muitas vezes o núcleo urbano dessa vila ficava muito longe e gerava as reivindicações dos moradores por facilidade de acesso a serviços espirituais e civis, ocasionando assim a elevação da capela à freguesia.

Duas grandes mudanças surgiam com a elevação da capela à freguesia. A primeira, e muito importante, consistia no poder civil que o templo religioso passava a exercer, já que nele ocorriam registros civis como batizados, casamentos e registros de óbitos. A freguesia se mantinha subordinada ao conselho da vila. A segunda mudança está relacionada ao território, que passava a ser delimitado pela demarcação do seu termo: o termo da freguesia.

Ao esclarecer a necessidade de uma capela passar à condição de freguesia, Maria Fernanda Derntl explica: 
Em 1765 se deu a elevação da Capela de Jaguari, entre conflitos de fronteira e uma intensa política de urbanização do sertão paulista. Desta forma, a pequena capela passaria a atender um número maior de fiéis, passando a exercer também funções civis. Uma nova torre foi construída e anexada à estrutura existente.

Nesta data, sob o nome de Freguesia de Nossa Senhora da Conceição do Jaguari, a freguesia inicia seus serviços civis, subordinada à Vila de São Paulo.

Figura 2: Imagem da primeira Capela com torre. Trata-se de uma pintura da Igreja após a elevação a Freguesia de Nossa Senhora da Conceição do Jaguari, Onde a Capela construída em 1963 tinha essa configuração cedendo sua estrutura para a construção da torre e 1765. (Pintor e data desconhecido).

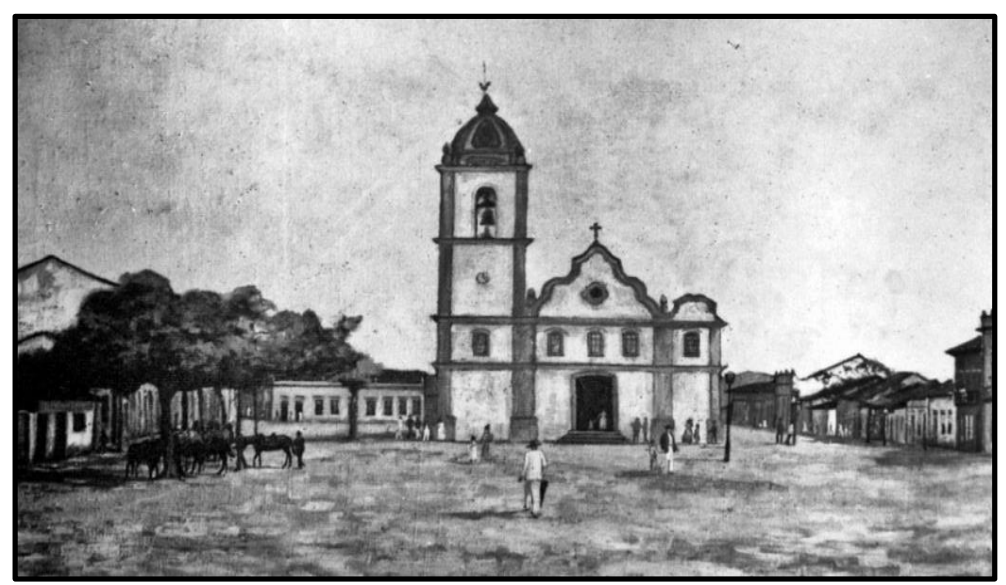

Fonte: Museu Municipal Oswaldo Russomano.

Com a capela elevada à condição de freguesia, era necessário delimitar o território (termo) da nova freguesia. Com isto, as populações dos bairros rurais e das capelas que estavam dentro do termo da freguesia passavam a ser os seus fregueses, cabendo ao pároco o registro, no seu livro tombo, dos nascimentos, óbitos e casamentos da população moradora no termo da freguesia. Como freguesia ela tinha, portanto, além da função religiosa, uma função civil, diferentemente da capela, que cuidava apenas dos paramentos religiosos.

Nos bairros rurais, a população se relacionava socialmente em torno de uma capela. No entanto, muitas vezes essas capelas eram construídas nas fazendas e sítios da região, em terras pertencentes a um sesmeiro. Enquanto não havia a doação de um patrimônio religioso, as capelas particulares não poderiam ser vinculadas a uma freguesia nem gerar fundos para o sustento de um pároco para exercer as funções religiosas.

Os Maços de População são os documentos censitários produzidos entre 1765 e 1850 e nos trazem a população das vilas da capitania de São Paulo. Assim, os dados sistematizados sobre a população da Freguesia de Nossa Senhora da Conceição do Jaguari têm início em 1767, conforme localizamos no Arquivo Público do Estado de São Paulo.

Este documento é fundamental para a compreensão da formação urbana do bairro rural de Jaguari. A confecção destas listas nos traz a quantidade de fogos existentes na vila, assim como 
o nome dos moradores: casal (geralmente vinha com sobrenome, indicação da patente militar e idade), filhos (apenas primeiro nome e idade), agregados (às vezes nome completo e idade) e escravos (nome e idade, mas em alguns anos apenas a quantidade total). As listagens foram elaboradas de acordo com as esquadras militares da qual faziam parte os habitantes (chefes de famílias) e divididas por bairros. Com isto, conseguimos estabelecer a quantidade de fogos da vila, o número de habitantes e, pelo número de escravos e a riqueza da sociedade em formação.

Os primeiros dados sobre a Freguesia de Nossa Senhora do Jaguari, aparecem em 1767, juntamente com informações sobre a Freguesia de São João do Atibaia (elevada à vila em 1769) e da Freguesia de Nossa Senhora da Conceição de Nazaré (elevada a vila em 1850). Em 1767 as três freguesias pertenciam à Cidade de São Paulo.

Entre 1769 e 1796 as informações sobre a Freguesia de Nossa Senhora da Conceição do Jaguari aparecem anexadas nos documentos da Vila de São João do Atibaia. A partir de 1798, após a elevação da Freguesia de Nossa Senhora da Conceição do Jaguari à condição de Vila de Nova Bragança em 1797, as informações são separadas da Vila de São João de Atibaia, gerando uma documentação exclusiva da Vila de Nova Bragança, até o ano de 1847, com alguns anos faltantes ou incompletos. Foram analisados os anos de 1767, 1775, 1785 e 1796 (anos que Jaguari esteve na condição de freguesia) especificamente esses anos foram selecionados devidos melhores condições de leitura e buscando dar um intervalo de aproximadamente 10 anos para analise, assim fornecendo embasamento para entender quais foram os primeiros bairros rurais da Freguesia de Nossa Senhora da Conceição do Jaguari.

A Freguesia de Nossa Senhora da Conceição do Jaguari era formada por uma grande extensão territorial (Figura 3). Seu termo original correspondia, aproximadamente, aos territórios dos atuais municípios de Socorro, Monte Alegre do Sul, Amparo, Pedra Bela, Pinhalzinho, Tuiuti e Vargem, desmembramentos esses que ocorreram nos séculos XIX e XX

Figura 3: Hipótese do termo da Freguesia de Nossa Senhora da Conceição do Jaguari em 1765. Fonte IBGE, elaborado pela autora, ano 2018.

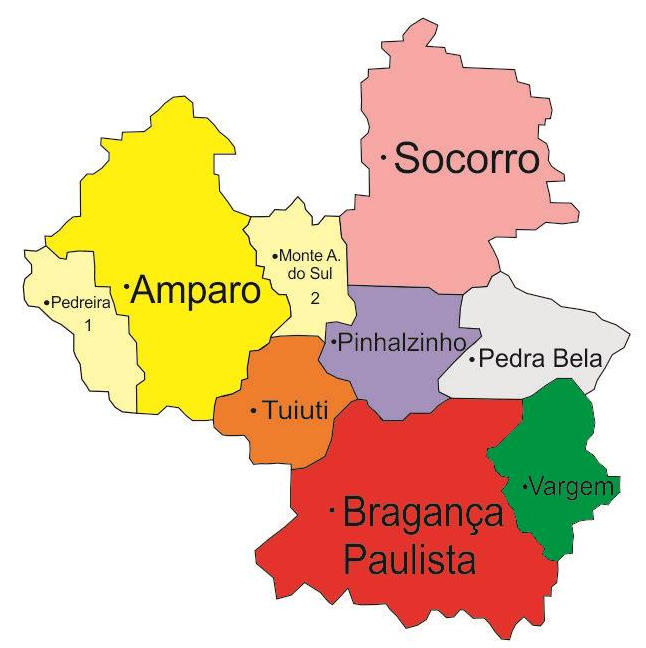




\section{Revista Nacional de}

Inicialmente a economia era voltada para a subsistência e em muitos casos existia na mesma propriedade o cultivo de arroz, milho e mandioca, além da criação de animais como bois e porcos. Com o tempo, a Freguesia de Nossa Senhora da Conceição do Jaguari desenvolveu uma economia mista, da qual agricultura e pecuária abasteciam o mercado consumidor da região, incluindo a cidade de São Paulo.

Há registros do número de fogos para os anos de 1767, 1775, 1785 e 1796, porém a informação é imprecisa por conta dos bairros que deixam de aparecer nos documentos em determinados anos. (Tabela 1)

Tabela 1: Relação de fogos e habitantes (brancos e negros) da Freguesia de Nossa Senhora da Conceição do Jaguari nos anos de 1767, 1775,01785 e 1796.

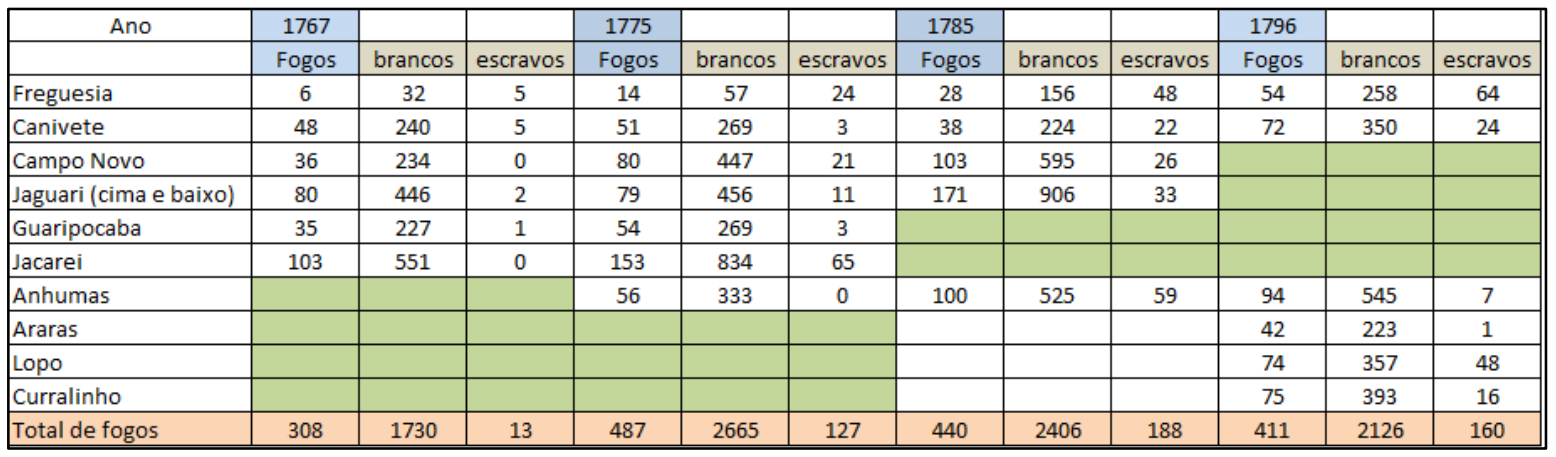

Fonte: “Maços de População” Atibaia e Nazareth. Arquivo Público do Estado de São Paulo.

Com base nas informações dos Maços de População, podemos constatar que os primeiros bairros rurais da Freguesia de Nossa Senhora da Conceição do Jaguari foram 10, com uma ocupação em direção ao Estado de Minas Gerais. 


\section{Revista Nacional de}

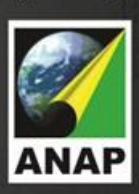

Gerenciamento de Cidades

Figura 4: Os Bairros Rurais de Freguesia de Nossa Senhora da Conceição do Jaguari na cartografia do IGC de 1909. Em vermelho, estão pontuados os bairros que constam no "Maço de População" de 1767, "1" hipótese de localização do Bairro Jaguari; Bairro da Freguesia, Canivete, Campo Novo, Guaripocaba e Jacarey; em verde integra-se "2" o bairro Anhumas, em 1775. Em 1785 não aparecem bairros novos e, finalmente, em amarelo aparecem os novos bairros de recenseados em 1796, Araraz, Lopo e Curralinho.

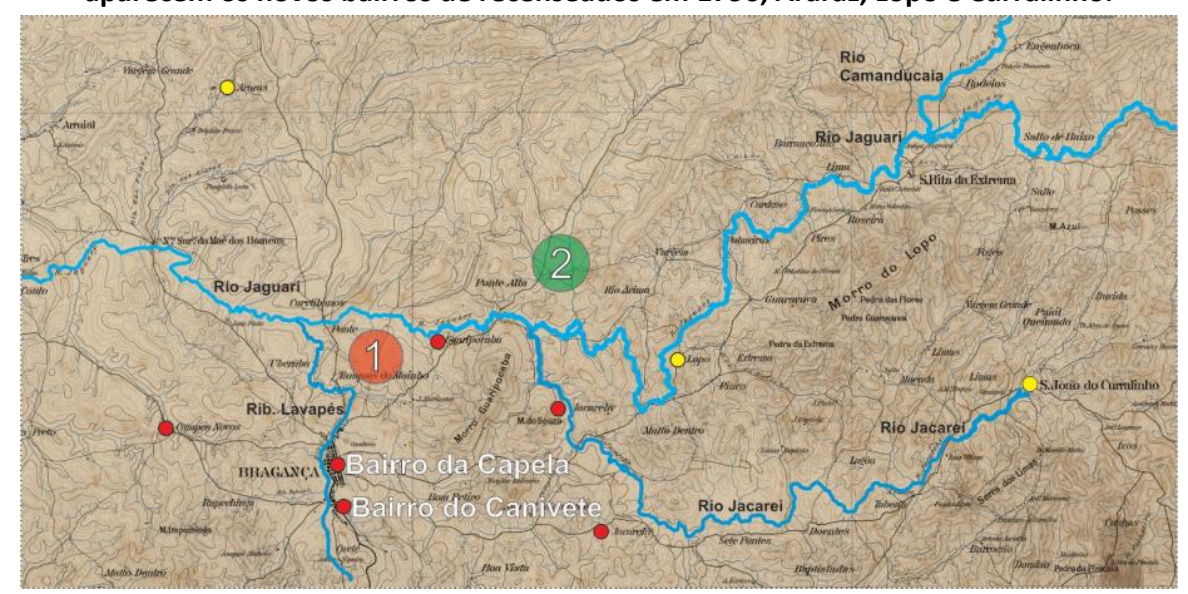

Fonte: Maços de População Maços de População de 1767, 1775, 1785 e 1796, usando como referência o mapa de 1909, elaborado e publicado pela Seç̧ão Cartográfica da Companhia Lith- Hartmann - Reichenbach, São Paulo e Rio- Arquivo Público do estado de São Paulo.

\section{O Bairro rural de Anhumas.}

O Bairro rural de Anhumas aparece pela primeira vez nos maços de população em 1775, um bairro que tem como limites de um lado o bairro do Guaripocaba, e o outro a região de conflito com a divisa de Minas Gerais, e também as Serras do Araraa e Anhumas. O Mapa organizado pelo Instituto Geográfico e Geológico em observância a Lei 5.285 de 18 de Fevereiro de 1959, assinado pelo Engenheiro Valdemar Lefreve, em 16 de outubro de 1957, nos revela um cenário com poucas mudanças no decorrer dos anos, no entanto com importâncias variadas conforme o processo econômico (corrida pelo ouro, economia mista, cafeicultura e implantação da Rodovia Fernão Dias).

Anhumas fez parte do território da cidade de Bragança Paulista até 1991, quando a cidade de Vargem foi criada pelo desmembramento de parte do território de Bragança Paulista. Neste processo, o bairro rural do Anhumas passou a fazer parte da cidade paulista de Vargem, que se localiza na divisa com o estado de Minas Gerais.

$\mathrm{O}$ bairro de Anhumas, nos dias de hoje, mantem praticamente a mesma configuração do século XIX, é um espaço rural, com uma estrada de terra que corta o pequeno espaço entre as serras as Serras do Araras e Anhumas até chegar à desativada estação de trem do bairro do Guaripocaba, no município de Bragança Paulista. Essa estrada teve grande importância no ir e vir dos viajantes bandeirantes que passavam a caminho de Minas Gerais ou São Paulo, e foi nessa estrada que surgiram capelas e produtores que abasteciam esses viajantes, e também absorviam as mercadorias vindas de Minas Gerais. 


\section{Revista Nacional de}

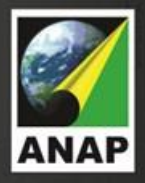

Gerenciamento de Cidades

Foi nessa estrada que grande parte de produção cafeeira do século XIX passava vinda de Minas Gerais para seguir para o porto de Santos, antes e depois da ferrovia Bragantina, fundada em 1884, sendo um dos pontos de partida da Estrada de Anhumas a Estação Ferroviária do Guaripocaba que se mantém conservada até hoje. A população se firmou ao longo dessa estrada principal, e ao logo da mesma foram erguidas igrejas, capelas que formam um rico acervo histórico arquitetônico.

No ano de 1775 o Bairro rural de Anhumas aparece pela primeira vez e apresenta 56 fogos, 333 moradores brancos e nenhum escravo, já no ano de 1785, esse número cresce para 100 fogos, 525 moradores brancos e 59 escravos, (tabela 1) além de vendas e comércios no decorrer da principal estrada que cortava o bairro. São aproximadamente $22 \mathrm{Km}$ que abriga atualmente centenas de famílias, e ligava o bairro rural do Campo Místico, (atual cidade de Pedra Bela) ao núcleo urbano da Freguesia de Nossa Senhora da Conceição do Jaguari, tendo sido a principal opção para se chegar a Minas Gerias antes da implantação da rodovia Fernão Dias. Partindo de Minas Gerias em direção ao território paulista, encontramos ao longo da estrada do bairro rural de Anhumas:

Figura 5: Estrada do Bairro Rural Anhumas, onde 1: Capela Santa Teresa; 2: Capela São Benedito; 3: Capela Nossa Senhora Aparecida/ Santa Rita de Cássia; 4: Capela do Bom Parto; 5: Capela do Belém e 6: Estação Ferroviária do Guaripocaba. Em verde o então bairro de Vargem, atual município.

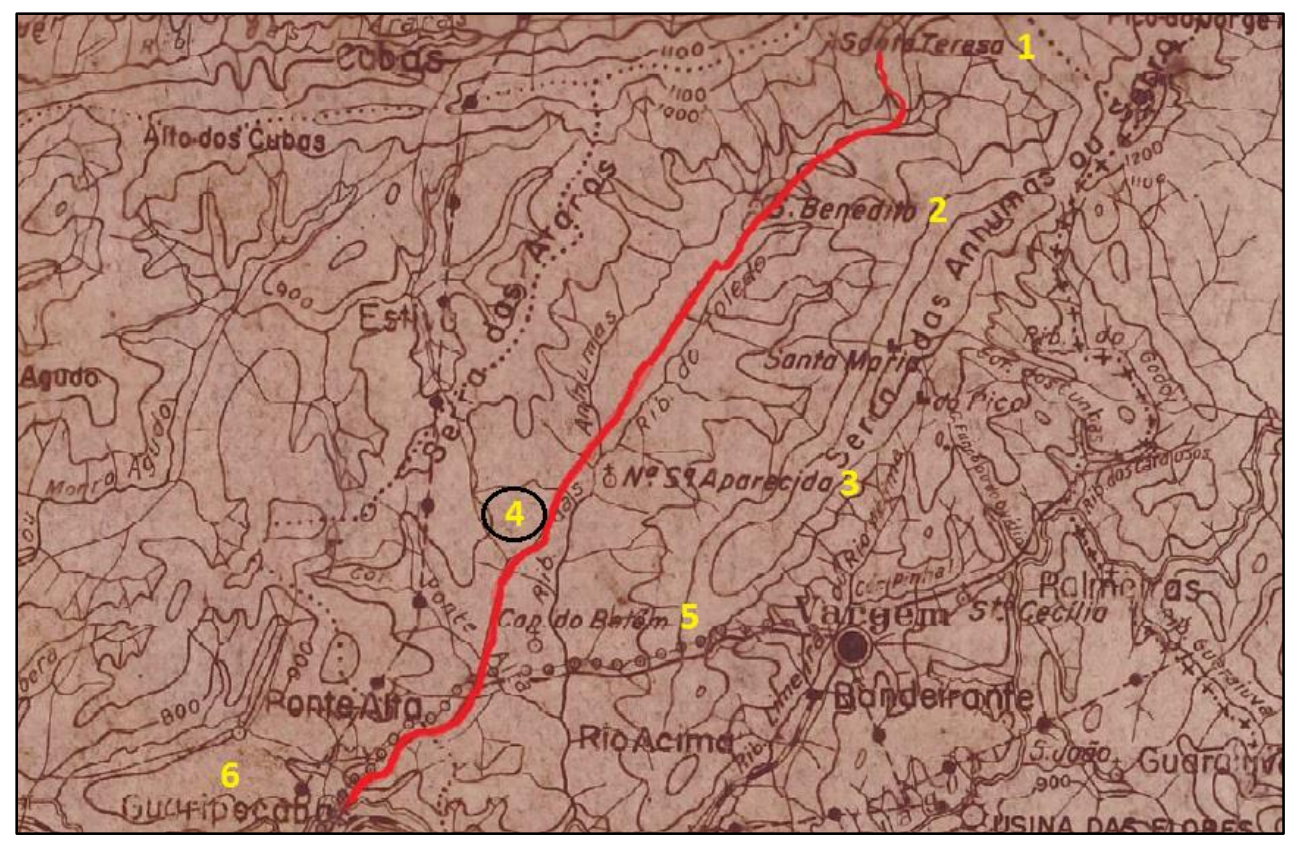

Fonte: Arquivo Público do Estado de São Paulo, mapa base organizado pelo Instituto Geográfico e Geológico. Assinado pelo Engenheiro Valdemar Lefreve, em 16 de outubro de 1957. 


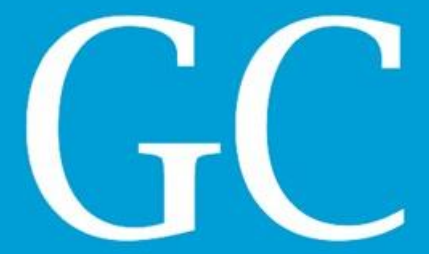

Revista Nacional de

10- A Fazenda Santa Tereza; (1 na figura 5) onde foi construída no inicio do século XIX a Igreja de Santa Tereza ( demolida em 1999) que havia sido construída por imigrantes Italianos vindos para a região.

Figura 6: Imagem da Capela da Fazenda Santa Teresa, demolida em 1999.

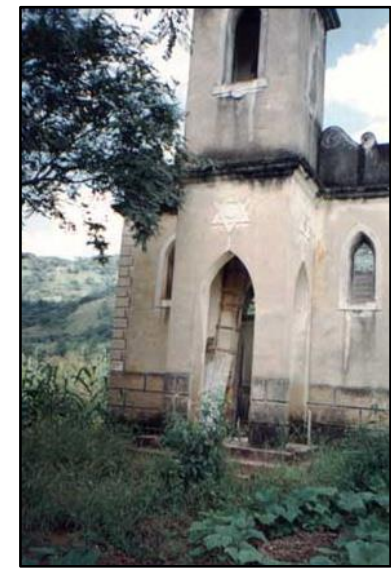

Fonte: BARLETTA, Almicar. Conhecendo a Região Bragantina. Pg.11.

2-- A Capela de São Benedito; (2 na figura 5) foi construída em devoção ao padroeiro do bairro no inicio do século XIX, e foi muito frequentada pelos viajantes que ali passavam, na frente existia um grande comércio, uma construção colonial para atender moradores e viajantes. 0 comércio não existe mais, e a Igreja de São Benedito foi totalmente descaracterizada após reforma no ano de 2015.

Figura 7, Comércio construído no período colonial em frente a Capela São benedito. Figura 8, Foto da capela em 2000 e Figura 9, Foto da Capela de São Benedito em 2018.
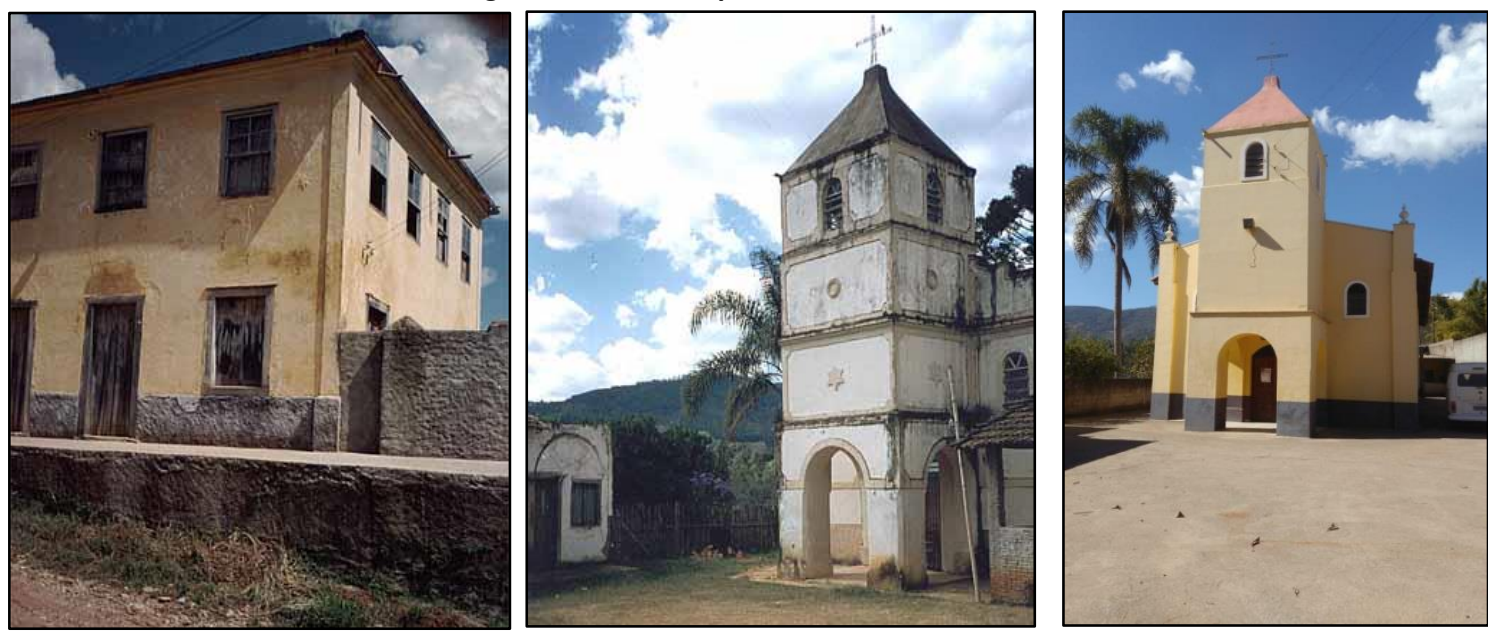

Fonte: figura 7 e 8 Fonte: BARLETTA, Almicar. Conhecendo a Região Bragantina. Pg.18 e figura 9 arquivo pessoal da autora. 
3o- A Capela de Nossa Senhora Aparecida, sem registro sobre sua demolição, porém nessa gleba desde o século XVIII funciona a Fazenda de Santa Rita, que hoje preserva a memória da época do cultivo do café do século XIX. Hoje, ali se encontra a sede da Capela Santa Rita, fazenda esta que cultiva atualmente cana-de-açúcar, banana e eucalipto, produtos que tomaram lugar da antiga produção de café. Nesta fazenda encontram-se, atualmente, duas Capelas, a do Bom Parto (4 na figura 5) e a de Santa Rita de Cássia (3 na figura 5), ambas construídas no fim do século XVIII. A Capela de Santa Rita tem no seu interior as imagens de Santa Rita, Nossa Senhora Aparecida, São Francisco, Santo Antônio, Nossa Senhora de Lourdes, São Martinho, Santa Terezinha, Nosso Senhor Jesus Cristo e possui pinturas de anjos feitas a mão no teto. A 300m da Capela de Santa Rita está a Capela do Bom Parto, construção colonial, próxima à antiga colônia de moradores da fazenda, desde os tempos que existiam o fluxo intenso de viajantes por aquela estrada, fluxo esse que diminuiu com a construção da rodovia Fernão Dias concluída em 1959. Em todas as "sextas feiras santas" a população se reúne para a tradicional e centenária procissão que sai da Capela do Bom Parto para a capela de Santa Rita, reunindo moradores dos bairros vizinhos.

Figura 10, Capela Nossa de santa Rita, Figura 11, capela Nossa Senhora do Bom Parto e Figura 12 a "Procissão da Sexta feira Santa" que acontece entre as duas capelas.
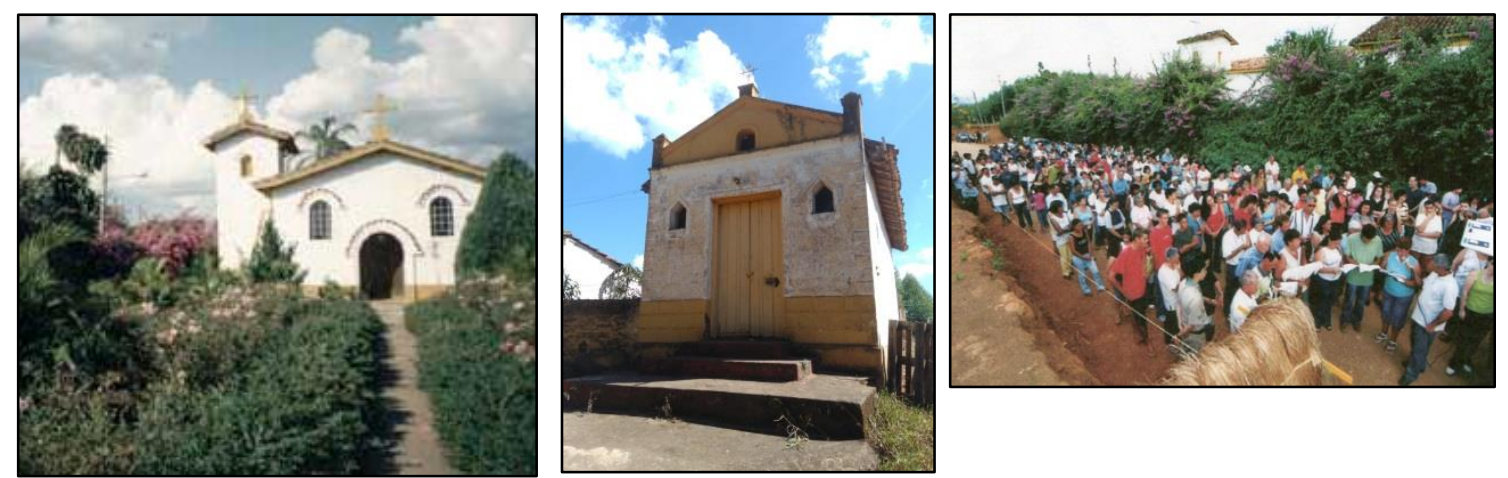

Fonte Figura 10: Fonte: figura 7 e 8 Fonte: BARLETTA, Almicar. Pg. 14. Fonte Figura 11 arquivo pessoal da autora. Fonte figura 12, Jornal da Vargem de 21 de abril 2018.

5o- A Capela de Belém, (5 na figura 5)situada no sítio Belém, é um autentico exemplar de uma construção colonial, feita de taipa e altar em madeira; atualmente passando por processo de restauro. Na frente dessa Capela, existia um comércio que hoje é residência do proprietário do Sítio Belém. No ano de 2017, o sr. Benedito Russi de Lima passou para Igreja Católica a doação do solo onde foi construída a Capela do Belém, para assim poder recolher verba para o restauro com mais facilidade. $O$ processo de doação do solo sagrado ainda segue os moldes do período colonial. 


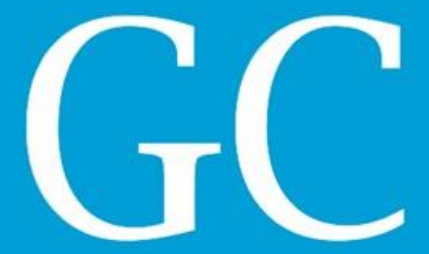

Revista Nacional de

Gerenciamento de Cidades

National Journal of Cities Management

Figura 13 imagem da Capela do Belém em 1999, e Figura 14 imagem da Capela do Belém em processo de restauro, ano 2018.
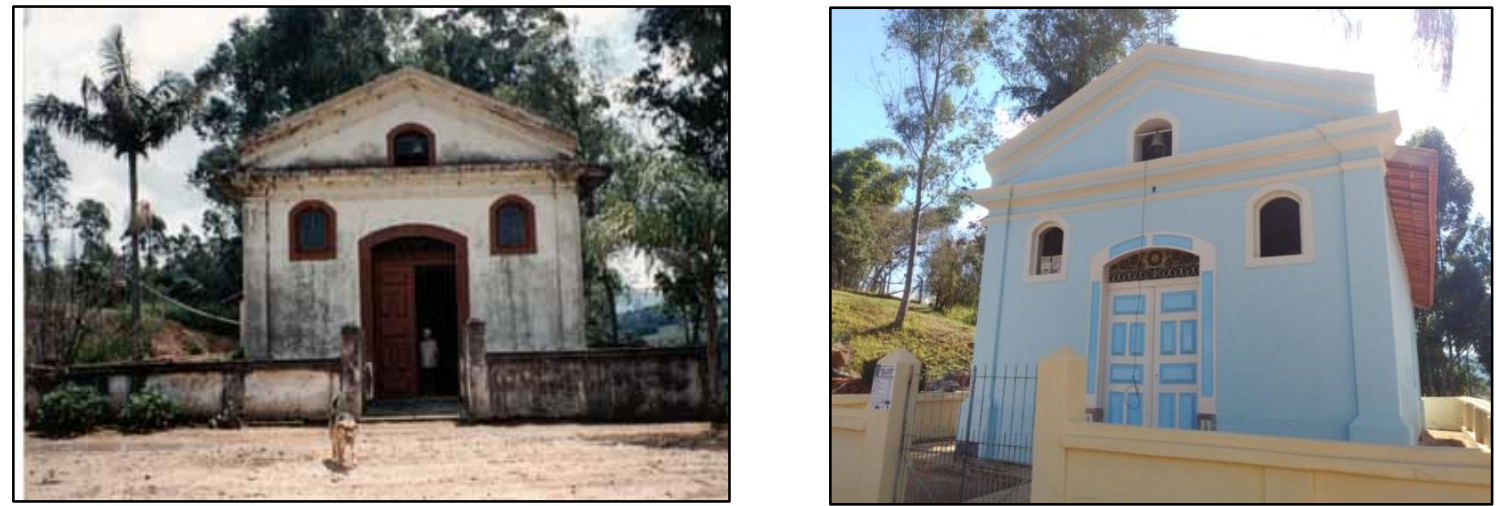

Fonte figura 12, BARLETTA, Almicar, pg. 12. Figura 13 arquivo pessoal da autora.

5o-A estação ferroviária Guaripocaba, (6 na figura 5) foi uma importante estação para o escoamento principalmente do café na região, além de passageiros. Entre 1884 e 1929, a estrada serviu a região bragantina e também a aristocracia rural da época, os chamados Barões do Café, no transporte da produção cafeeira. Eram sete estações, (Vargem, Guaripocaba, Curitibanos, Bragança, Taboão, Eng. Napoleão e Tanque) e a partir daí se interligava com o ramal de Atibaia, que também fazia parte de Ferrovia Bragantina, sendo seu destino final Jundiaí.

Figura 14, imagem da estação do Guaripocaba em funcionamento sem data. Figura 15 imagem da Estação do Guaripocaba em processo de restauro, 2018.

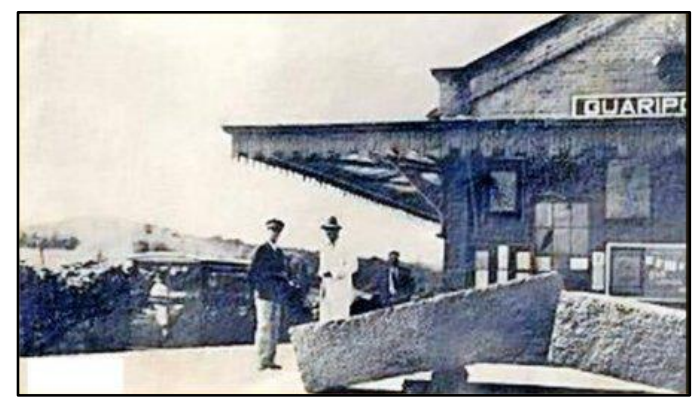

Fonte figura 14: www.cidadeecultura.com/estrada-deferro-bragantina (visitado em 12 de setembro 2018. Figura 15: arquivo pessoal da autora.

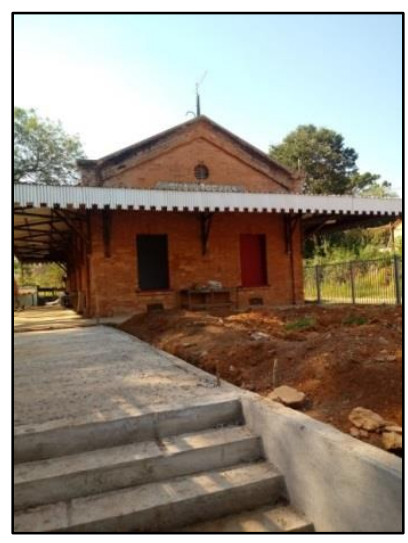




\section{Conclusão}

A compreensão da formação do território passa pelo entendimento do papel dos bairros rurais na formação de uma rede de caminhos, capelas, povoados, estruturas ferroviárias, entre outros, que guardam entre sí uma lógica própria, uma interdependência e uma hierarquia particular de cada formação territorial específica. Estudos de caso locais permitem resgatar a complexidade destas relações entre meio urbano e meio rural, assim como tornar acessíveis estas reconstituições para a população local que visa preservar o seu patrimônio. Para o caso do Bairro Rural de Anhumas, é absolutamente pertinente e viável gerar uma identidade cultural e passear pela história da região, em $22 \mathrm{~km}$ de estrada que ainda é de terra. Os primeiros habitantes daquele bairro foram registrados em documentação primária em 1775, a estrada ali formada era o principal acesso a Minas Gerais no período da corrida pelo ouro já no século XVIII. Hoje, nos $22 \mathrm{~km}$ desta estrada ainda encontram-se conservadas cinco Capelas. Esta constatação confirma que o modo português de fundar cidade, segundo nos esclarece Murilo Marx, destacando que a tendência após a implantação da capela era o povoado continuar a se desenvolver, ganhando autonomia, passando para freguesia e posteriormente à vila, pode ser verificada em vários casos da região.

Todavia, nem toda capela era elevada a freguesia e nem toda freguesia era elevada a vila, como no caso do Bairro de Anhumas. No percurso da Estrada de Anhumas destaca-se a construção da Estação de Ferroviária do Guaripocaba no período em que a economia cafeeira se desenvolve na região. Se por um lado, a construção desta estação ferroviária dinamizou o bairro, com sua desativação o bairro retorna ao seu aspecto rural, como na sua origem.

Portanto, o que para muitos é um singelo bairro rural no território paulista, na cidade de Vargem, com 10.834 habitantes em 2010, segundo o IBGE, trata-se na verdade de um rico conjunto "vivo" de relações sociais e patrimônios simbólicos historicamente importantes que estabelece a comunhão de determinados valores entre os membros da sociedade local, formando uma paisagem cultural que deve ser valorizada.

\section{AGRADECIMENTO}

Coordenação de Aperfeiçoamento de Pessoal de Nível Superior - CAPES.

\section{REFERÊNCIAS BIBLIOGRÁFICAS}

ARQUIVO PÚBLICO DO ESTADO DE SÃO PAULO. Maços de População da Vila de São João do Atibaia. São Paulo. BARLETTA, Almicar. Conhecendo a Região Bragantina. Editora da Universidade São Francisco- EDUSF, 2000.

BELLOTTO, Heloísa Liberalli. Autoridade e conflito no Brasil colonial: o Governo do Morgado de Mateus em São Paulo (1755 - 1775), São Paulo: Editora Alameda, 2007.

BUENO, Beatriz Piccolotto Siqueira. "Dilatação dos confins: caminhos, vilas e cidades na formação da Capitania de São Paulo (1532-1822)", Anais do Museu Paulista, vol.17, n.2, São Paulo, 2009, p. 251 - 294. 


\section{Revista Nacional de}

Gerenciamento de Cidades

National Journal of Cities Management

DERNTL, Maria Fernanda. Método e Arte: Criação Urbana e Organização Territorial na Capitania de São Paulo, 1765-1811. Tese de Doutorado da FAU-USP, São Paulo, 2010.

Fonseca, C. D. Arraiais e vilas D`El Rei: espaço e poder nas Minas setecentistas. Belo Horizonte: Editora UFMG. 2011.

JUCÁ Neto, Clovis Ramiro. Primórdios da Urbanização no Ceará. Fortaleza, Ed. UFC, 2013.LAURITO, Domingos;

MARX, Murilo. Cidade no Brasil: terra de quem? São Paulo: Nobel; Editora da Universidade de São Paulo. 1991.

NUNES, Carolina Gonçalves. Formação do Território e Espaço Urbano de Bragança Paulista: Dos Primórdios a 1830. Dissertação de mestrado em Urbanismo da Pontifícia Universidade Católica de Campinas, FAU - PUCAMP, Campinas, 2017.

SALGADO, Ivone; PEREIRA, Renata Baesso. A formação da rede urbana como estratégia de definição da fronteira entre as Capitanias de Minas Gerais e de São Paulo na segunda metade do século XVIII. LABOR \& ENGENHO, v. 11, p. 218-241, 2017. 